\title{
Self-adjusted postmenopausal hormone replacement therapy: effects on the biological and immunological profile of FSH and correlation to climacteric symptoms
}

\author{
Tarja Vihtamäki ${ }^{1}$, Manuela Simoni ${ }^{2}$, Risto Tuimala ${ }^{1}$, Eberhard Nieschlag ${ }^{2}$ and Kimmo K Vihko ${ }^{1,3}$ \\ ${ }^{1}$ Department of Obstetrics and Gynecology, Tampere University Hospital, Tampere, Finland, ${ }^{2}$ Institute of Reproductive Medicine of the University of \\ Münster, Münster, Germany and ${ }^{3}$ Department of Obstetrics and Gynecology, Turku University Central Hospital, Turku, Finland
}

(Correspondence should be addressed to K Vihko, Department of Obstetrics and Gynecology, Turku University Central Hospital, Kiinamyllynkatu 4-8, FIN-20520, Turku, Finland)

\begin{abstract}
Objective: The purpose of the present study was to evaluate the hormonal profile of patients of postmenopausal age during estrogen replacement therapy (ERT) with special reference to the serum levels of biologically active FSH (B-FSH) in a self-adjusted ERT model.

Design: The hormonal values found have been correlated to climateric symptoms reported by the patients (scored by the Kupperman menopausal index (KI)).

Methods: B-FSH was measured using an assay based on a cell system transfected permanently with FSH receptor cDNA. All women $(n=32)$ applied estradiol percutaneously using $1 \mathrm{mg}$ estradiol$17 \beta\left(\mathrm{E}_{2}\right)$ as an initial dose and were encouraged to increase the daily dose until they felt comfortable according to a specific scheme. Twelve of the 32 women were hysterectomized and treated, accordingly, with ERT only; 20 women received megestrol acetate monthly for 10 days.

Results: The initial average KI was 30 (range 10-54). A high degree of correlation $(r=0.83$; $P<0.001$ ) was observed between B-FSH and immunologically active FSH (I-FSH). Serum I-FSH and $\mathrm{E}_{2}$ correlated negatively $(r=-0.21 ; P<0.001)$; similarly, a negative correlation $(r=-0.15$; $P<0.01)$ was observed between serum B-FSH and $E_{2}$ levels. Serum I-FSH and KI showed modest but significant positive correlation $(r=0.13$; $P<0.01)$; a somewhat higher degree of correlation $(r=0.19 ; P<0.005)$ was observed when B-FSH and KI were compared. $\mathrm{E}_{2}$ showed positive correlation to serum sex-hormone binding globulin levels $(r=0.22 ; P<0.001)$.

Conclusions: This study shows that the transdermal self-adjusted hormone replacement therapy (HRT) model introduced is suitable for studies on endocrine changes during postmenopausal ERT. The finding of poor correlation between serum $\mathrm{E}_{2}$ levels and $\mathrm{KI}$ emphasizes the importance of hormonal measurements during postmenopausal HRT.
\end{abstract}

European Journal of Endocrinology 146 333-338

\section{Introduction}

The perimenopause is characterized by decreasing secretion of ovarian sex steroids resulting in climacteric symptoms, the most notable of which are hot flushes. These symptoms are due to decreased levels of serum estradiol-17ß $\left(\mathrm{E}_{2}\right)$ resulting in instability of body-temperature regulation (for review, see $(1,2)$ ).

In some clinical settings, such as symptoms typical of climacterium in patients in their late 30 s or early 40 s, it may become important to evaluate the endocrine status of the patient with regard to menopause by evaluating the serum levels of gonadotropins and/or sex steroids. In general, measurements of serum folliclestimulating hormone (FSH) are used for these situations since FSH levels are known to be increased already early during premenopause $(3-5) . \quad E_{2}$ measurements have limited value due to the high interindividual and menstrual cycle-related intra-individual variation.

Climacteric symptoms in the Nordic countries are generally treated by peroral or transdermal $E_{2}$ or $E_{2}$ valerate therapy. The decrease in the experiences of hot flushes is generally considered as a sign of effective therapy. The relief of symptoms does not, however, correlate well with achievement of therapeutic levels of serum $E_{2}(6,7)$ with regard to prevention of diseases, such as osteoporosis, believed to be related to cessation of ovarian function at menopause. The serum levels of $E_{2}$ are not followed routinely as there is no general consensus on the serum levels required with reference to protection against different diseases believed to be induced by postmenopausal estrogen replacement therapy (ERT). 
Since serum FSH levels have become a routine marker for estimation of patients' perimenopausal status they might also serve as a marker of effective therapy. It is known that FSH is secreted from the pituitary as various iso-hormones $(8,9)$ differing for example in their glycosylation pattern, resulting in multiple proteins in isoelectric focusing (10). To understand better the value of serum FSH measurements during ERT, we have now measured the levels of this gonadotropin in a patient group using self-adjusted trandermal ERT. In addition to conventional immunological measurements, we have measured the biopotency of FSH using a cell-based assay. The hormonal values found have been correlated to each other and to climacteric symptoms reported by the patients.

\section{Materials and methods}

\section{Patients}

The patient group consisted of 32 healthy postmenopausal women with severe climacteric symptoms. The age range was from 51 to 59 years and the mean body weight was $73 \mathrm{~kg}$. The time from the last menstrual period was more than 6 months in all patients before ERT was started; no patient had contraindications against ERT. The study was carried out according to good clinical practice (GCP); clinical office investigations included general clinical and gynecological investigation (including breast examination).

\section{ERT}

All women applied $\mathrm{E}_{2}$ (Estrogel; Leiras Oy, Turku, Finland) percutaneously using $1 \mathrm{mg} \mathrm{E}_{2}$ as the initial dose. The patients were encouraged to increase the daily dose by $0.5 \mathrm{mg}$ every 2 weeks until they felt comfortable. Each participant continued the treatment for at least 3 months. The patients were taught the use of the gel by the first author of the present study; during monthly visits the use of gel was checked and compared with documentation according to GCP. Twelve of the 32 women were hysterectomized and treated, accordingly, with ERT only; 20 women received megestrol acetate (Megestin; Leiras Oy) $10 \mathrm{mg} /$ day monthly for induction of withdrawal bleeding.

\section{Recording of climacteric symptoms}

The study participants were asked to answer a questionnaire concerning their symptoms before therapy was started and each time before increasing the dose. The evaluated symptoms consisted of sweating, experiences of hot flushes, paresthesias, insomnia, nervousness, depression, vertigo, fatigue, pain in joints or muscles, headache, experiences of palpitation and itching. Each symptom was scored according to the
Kupperman menopausal index (KI). The initial average KI was 30 (range 10-54).

\section{Hormonal measurements}

Venous forearm blood samples were drawn at baseline visit, every time the dose was increased, and at the end of the study. The blood samples were obtained $12 \mathrm{~h}$ after gel application.

Serum $\mathrm{E}_{2}$ concentration was monitored by RIA (Estradiol-2; Sorin Biomedica, S.p.A., Saluggia, Italy). Immunologically active FSH (I-FSH) was monitored by the Delfia immunofluorometry technique (Wallac Oy, Turku, Finland).

Biologically active serum FSH (B-FSH) was monitored essentially as described earlier (11) using a cell system transfected permanently with FSH receptor (FSHR) cDNA. This method has been validated in detail (9) and used for analyses on female (11) and male (12) serum FSH. The FSH data are expressed as U/l according to the generally accepted principles for immunoassays and bioassays (5) using WHO FSH standard $78 / 549$ as the standard preparation.

Serum sex-hormone binding globulin (SHBG) levels were detected by the Delfia technique (Wallac Oy).

\section{Statistical analyses}

The significances of observed changes in different hormonal parameters were evaluated by Wilcoxon's test. For association analyses between different parameters, Spearman's correlation coefficients were used.

\section{Results}

The correlation between B-FSH and I-FSH in postmenopausal sera is shown in Fig. 1. A high degree of correlation $(r=0.83 ; P<0.001)$ was observed between these two parameters. In individual patients, there were up to 3-fold differences in the B-FSH/I-FSH ratio at individual time points.

Serum I-FSH and $\mathrm{E}_{2}$ correlated negatively $(r=-0.21 ; P<0.001 ;$ Fig. 2$)$; similarly, a negative correlation $(r=-0.15 ; \quad P<0.01)$ was observed between serum B-FSH and serum $\mathrm{E}_{2}$ levels (Fig. 3).

Serum I-FSH and climacteric symptoms, evaluated by collecting KIs, showed weak positive significant correlation $(r=0.13 ; P<0.01)$ (Fig. 4). A somewhat higher degree of correlation $(r=0.19 ; P<0.005)$ was observed when B-FSH and KI were compared (Fig. 5). The correlation between $\mathrm{E}_{2}$ and KI values did not reach significance (data not shown).

$\mathrm{E}_{2}$ showed positive correlation to serum SHBG levels $(r=0.22 ; P<0.001)$ (Fig. 6). 


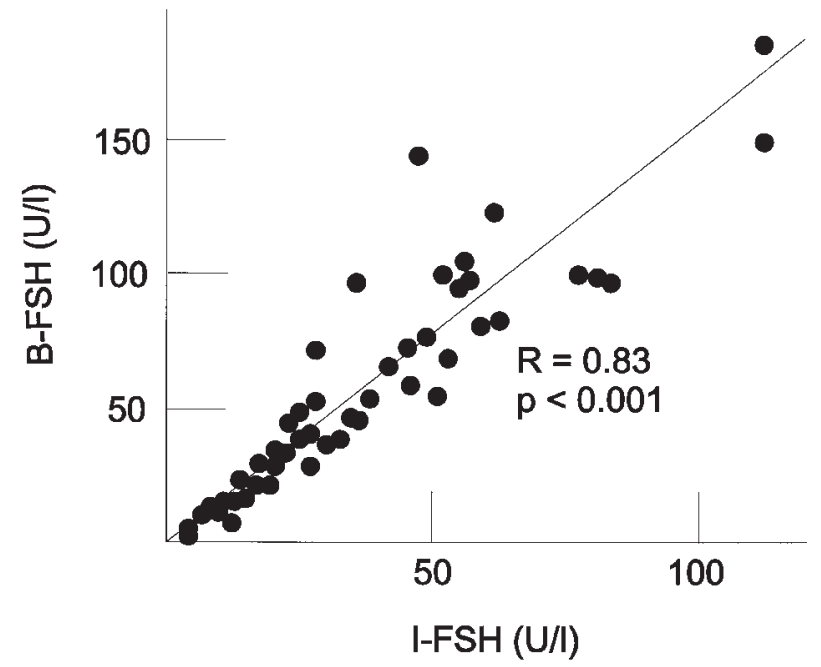

Figure 1 Regression plot analysis of serum B-FSH and I-FSH measured by a permanently transfected cell model assay and an immunofluorometric assay respectively. The serum samples were obtained from a postmenopausal patient group using transdermal ERT according to a self-adjustable protocol. FSH activities are expressed according to internationally accepted standards for these assays.

\section{Discussion}

The purpose of the present study was to evaluate the hormonal profile of patients of postmenopausal age during ERT with special reference to the levels of serum B-FSH in our self-adjusted ERT model. The results of the study show that (i) serum B-FSH and I-FSH levels show a high degree of correlation in

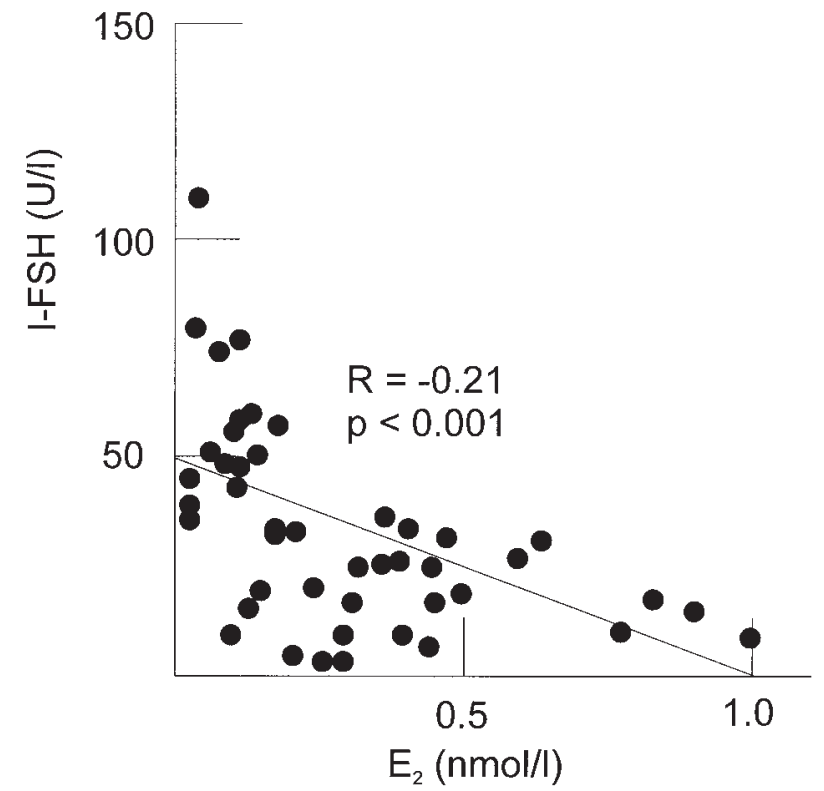

Figure 2 Correlation analysis between serum I-FSH and $\mathrm{E}_{2}$ in a group of postmenopausal women using transdermal HRT. The hormone levels are measured by Delfia and RIA respectively.

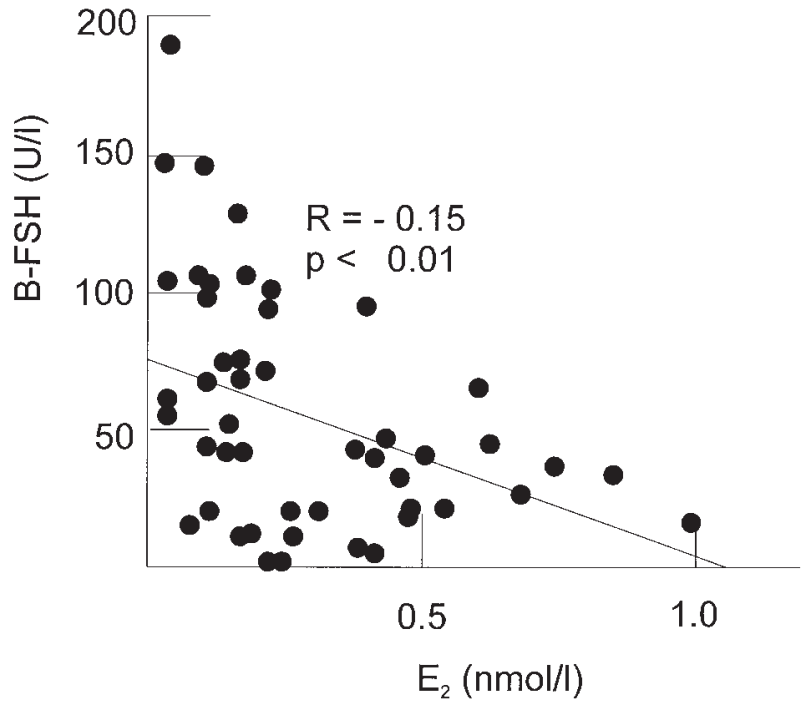

Figure 3 Regression analyses on serum $\mathrm{B}-\mathrm{FSH}$ and $\mathrm{E}_{2}$ in patients using ERT. The FSH levels are measured by a cell model permanently transfected with the FSHR. The $\mathrm{E}_{2}$ levels are measured by RIA. B-FSH levels are indicated using an internationally accepted reference preparation.

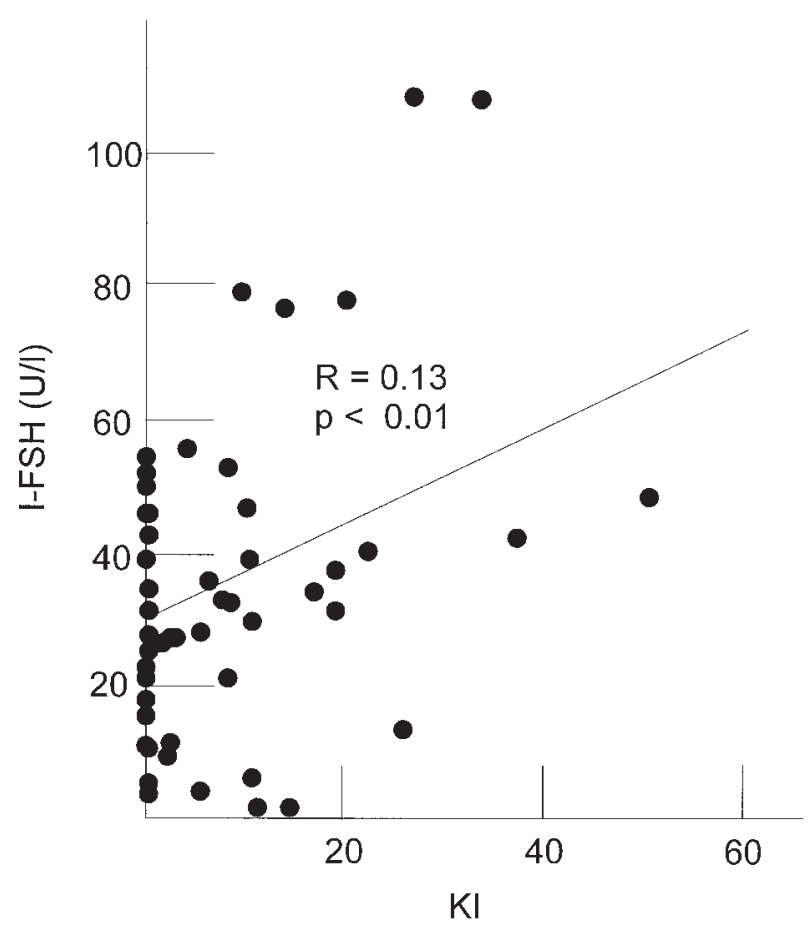

Figure 4 Correlation between serum I-FSH and climacteric symptoms reported by postmenopausal women on transdermal ERT; non-hysterectomized patients used periodic medroxyprogesterone acetate as well. The climacteric symptoms are collected by standard Kupperman's Index analyses; the number of total points is shown. The hormonal measurements were performed by Delfia. 


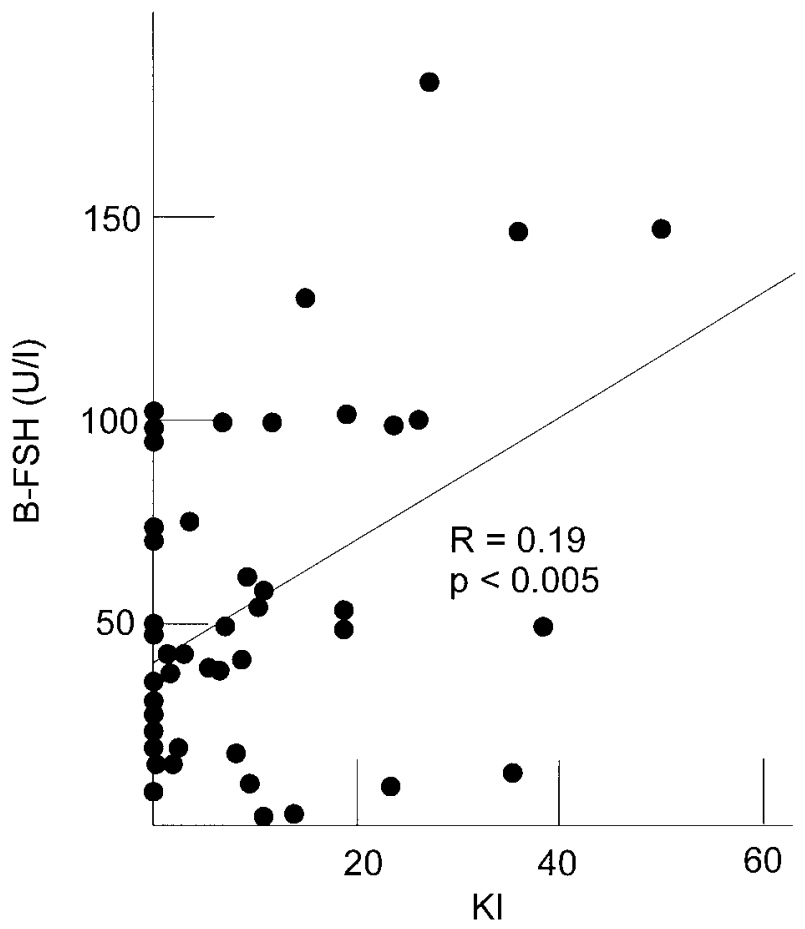

Figure 5 Regression plot analysis of serum B-FSH and climacteric symptoms in a group of women using HRT against climacteric symptoms. FSH levels are measured by a cell model permanently transfected with the FSHR. The climacteric symptoms are indicated as points obtained in the standard Kupperman's Index analyses.

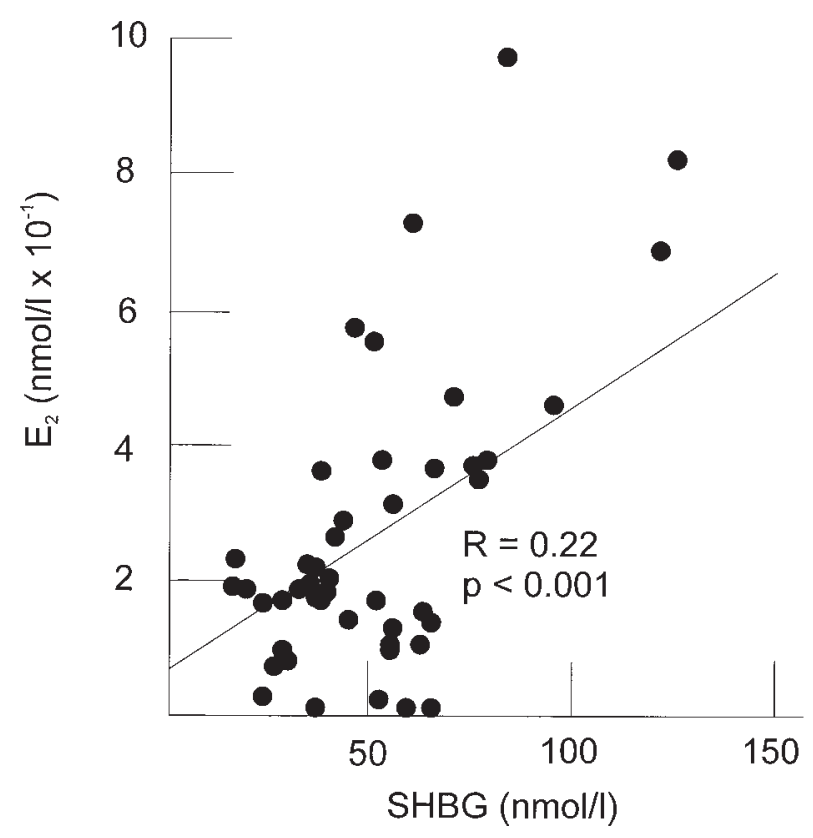

Figure 6 Correlation of serum $\mathrm{E}_{2}$ and SHBG levels in patients using transdermal $\mathrm{E}_{2}$ gel. The measurements were performed by immunofluorometry (Delfia). postmenopausal patients during hormone replacement therapy (HRT); (ii) in individual patients, the B-FSH levels are up to 3-fold higher than the I-FSH at certain time points during HRT; (iii) both serum B-FSH and I-FSH correlate negatively to serum $\mathrm{E}_{2}$ levels; (iv) I-FSH and B-FSH correlated weakly but positively with climacteric symptoms; and (v) serum $\mathrm{E}_{2}$ correlated positively with serum SHBG levels.

Serum FSH level measurements are ordered for various clinical indications (for review, see (5)). Among these, the most typical clinical situation is the evaluation of the menopausal status of patients suffering from symptoms typical of menopause, e.g. already in their early 40s. Serum FSH levels increase already early in menopause (13) and are generally considered as the most reliable laboratory parameter of the onset of perimenopause.

Several studies have indicated that FSH secreted by the pituitary consists of various molecular forms of the gonadotropin generally referred to as different isohormones (for review, see $(8,9)$ ). These isohormones are due to, for example, differential posttranslational modification of the core protein resulting in, for example, differential glycosylation patterns of the hormone.

Serum FSH levels are traditionally measured using immunometric assays (for review, see (5)). These methods measure the protein levels of the hormone, but do not evaluate the biological activity of the gonadotropin. Several studies (14-16) have shown that, in different clinical settings, differences in the biological activity may be found although immunometric assays indicate no alterations in hormone levels, suggesting that the molecular modification of the hormone protein is an important regulatory step in regulation of gonadotropin action. These findings have led to the development of cell-based assays where, typically, cells are permanently transfected with FSHRs; the bioactivity of FSH is, in these models, estimated by the altered production of, for example, second messengers such as cAMP (for review, see (17)). The method used in this paper (11) is amongst the first recombinant DNA methods described for these measurements and shows good sensitivity (less than $3 \mathrm{U} / \mathrm{l}$ ) and specificity when compared with other trophic hormones.

HRT is widely used in the Western countries in women of peri- and postmenopausal age. HRT relieves climacteric symptoms and is generally believed to protect against diseases typical of the elderly population such as osteoporosis (for review, see (18-22)). Unfortunately, many women discontinue the use of HRT after a couple of years, mainly because of fear of cancer and advice by physicians (23). There is no consensus, at present, whether serum $\mathrm{E}_{2}$ levels should be followed during ERT; however, it has been pointed out by us and other authors that the relief of climacteric symptoms does not necessarily guarantee protection against osteoporosis and other diseases of elderly 
women believed to be related to the deficiency of $E_{2}(6$, $7,24)$. To investigate these questions, we have developed a self-adjusted model of HRT based on a model where patients increase their daily $\mathrm{E}_{2}$ use until they feel comfortable with the medication $(6,7)$. The results from these studies have indicated that some patients feel comfortable although low levels of serum $\mathrm{E}_{2}$ are observed.

Transdermal $\mathrm{E}_{2}$ is as effective a regimen as peroral HRT (25-27). The benefit over peroral therapy and patches lies in the possibility to self-adjust the daily dose individually. For scientific studies, the gel offers an interesting model for studies on endocrine changes and climacteric symptoms during HRT and enables detailed correlation analyses of serum $\mathrm{E}_{2}$ levels against various other endocrine and/or clinical parameters.

In general, serum FSH levels correlated well to serum $\mathrm{E}_{2}$ levels in our patient group. This finding suggests that increases in serum $\mathrm{E}_{2}$ during postmenopause result in a negative feedback effect on the pituitary similar to that which occurs in women of reproductive age. Both B-FSH and I-FSH were decreased, suggesting the existence of decreased synthesis/secretion by the pituitary due to increased levels of serum $E_{2}$.

B-FSH correlated highly to I-FSH suggesting further that the negative feedback effect observed is primarily due to decreased synthesis/secretion of FSH by the pituitary. However, in individual patients the B-FSH/I-FSH ratio was increased up to threefold suggesting that, in some women, the B-FSH is increased while the gonadotropin protein level is increased more modestly. This finding suggests that, in some patients, the molecular nature of secreted FSH is altered. Further analyses of these sera may reveal what this finding is related to at the molecular level.

B-FSH and I-FSH correlated to climacteric symptoms as indicated by correlation analyses between these parameters and KIs. This finding also emphasizes the physiological importance of gonadotropins in the experience of hot flushes that are known to coincide temporally with gonadotropin surges from the pituitary (28). Many patients had no climacteric symptoms but still the gonadotropin levels were at postmenopausal level; however, most patients with severe symptoms showed high serum FSH levels.

No studies are available, at present, systematically comparing serum FSH or serum $\mathrm{E}_{2}$ with the degree of osteoporosis in patients on ERT/HRT. Therefore, it is not possible, at the moment, to estimate whether measurement of serum levels of hormones should be carried out in these patients, and whether we should preferentially measure serum FSH or serum $E_{2}$. At present, few physicians, at least in Finland, follow patients' serum $\mathrm{E}_{2}$ during ERT; this is in part due to high interindividual variation. It would be interesting to find out whether more constant results would result if serum FSH measurement were performed instead of serum $\mathrm{E}_{2}$ measurements.
Serum $\mathrm{E}_{2}$ correlated well with serum SHBG levels. The finding suggests that even with transdermal therapy, SHBG production/secretion is induced. Transdermal HRT is generally believed to by-pass the firstpass liver metabolism resulting in smaller changes in liver metabolism than with peroral ERT therapy. Similar effects on serum SHBG levels during transdermal gel HRT have also been shown previously by other investigators (26).

In conclusion, this study shows that the transdermal self-adjusted HRT model introduced is highly suitable for studies on endocrine changes during postmenopause. Serum FSH may be a better indicator of effective therapy than serum $E_{2}$. In most patients, serum B-FSH correlates closely with I-FSH levels. In individual patients, the B-FSH/I-FSH ratio is increased, suggesting the existence of an altered molecular nature of FSH secreted by the pituitary during postmenopausal HRT.

\section{References}

1 Avis NE, Kaufert PA, Lock M, McKinley SM \& Vass K. The evolution of postmenopausal symptoms. Baillière's Clinical Endocrinology and Metabolism $1987617-32$.

2 Richardson SJ. The biological basis of the menopause. Baillière's Clinical Endocrinology and Metabolism 19936 273-311.

3 Vihko KK, Kujansuu E, Mörsky P, Huhtaniemi I \& Punnonen R. Gonadotropins and gonadotropin receptors during the perimenopause. European Journal of Endocrinology 1996134 357-361.

4 Vihko KK. Gonadotropins and ovarian gonadotropin receptors during the perimenopausal transition period. Maturitas 1996 23 S19-S22.

5 Rose MP, Das REG \& Balen AH. Definition and measurement of follicle stimulating hormone. Endocrine Reviews 200021 5-22.

6 Tuimala R \& Vihtamäki T. Individual hormone replacement therapy. Maturitas 23 S87-S90.

7 Vihtamäki T \& Tuimala R. Can climacteric women self-adjust therapeutic estrogen doses using symptoms as markers? Maturitas 199828 199-203.

8 Chappel SC. Heterogeneity of follicle-stimulating hormone: control and physiological function. Human Reproduction Update 19951 479-487.

9 Ulloa-Aguirre A, Midgley AR Jr, Beitins IZ \& Padmanabhan V. Follicle stimulating isohormones: characterization and physiological relevance. Endocrine Reviews 199516 765-787.

10 Matikainen T, De Leeuw R, Mannaerts B \& Huhtaniemi I. Circulating bioactive and immunoreactive recombinant human follicle stimulating hormone (Org 32489) after administration to gonadotropin-deficient subjects. Fertility and Sterility $1994 \mathbf{6 1}$ 62-69.

11 Gudermann T, Brockmann H, Simoni M, Gromoll J \& Nieschlag E. In vitro bioassay for human follicle-stimulating hormone (FSH) based on L cells transfected with recombinant rat FSH receptor: validation of a model system. Endocrinology $1994 \mathbf{1 3 5}$ 2204-2213.

12 Simoni M, Peters J, Behre HM, Kliesch S, Leifke E \& Nieschlag E. Effects of gonadotropin-releasing hormone on bioactivity of follicle-stimulating hormone (FSH) and microstructure of $\mathrm{FSH}$, luteinizing hormone and sex-hormone binding globulin in a testosterone-based contraceptive trial: evaluation of responders and non-responders. European Journal of Endocrinology 1996 $135433-439$.

13 Sherman BM \& Korenman SG. Hormonal characteristics of the human menstrual cycle throughout reproductive life. Journal of Clinical Investigation $1976 \mathbf{5 5}$ 699-706. 
14 Jaakkola T, Ding Y-Q, Kellokumpu-Lehtinen P, Valavaara R, Martikainen H, Tapanainen J et al. The ratios of serum bioactive/ immunoreactive luteinizing hormone and follicle-stimulating hormone in various clinical conditions with increased and decreased gonadotropin secretion: reevaluation by a highly sensitive immunometric assay. Journal of Clinical Endocrinology and Metabolism 199070 1496-1505.

15 Matikainen T, Ding Y-Q, Vergara M, Huhtaniemi I, Couzinet B \& Schaison G. Differing responses of plasma bioactive and immunoreactive follicle-stimulating hormone and luteinizing hormone to gonadotropin-releasing hormone antagonist and agonist treatments in postmenopausal women. Journal of Clinical Endocrinology and Metabolism 199275 820-825.

16 Matikainen T, Haavisto A-M, Permi J, de Kretser D \& Huhtaniemi I. Effects of oestrogen treatment on serum gonadotropin bioactivity, immunoreactivity and isohormone distribution, and on immunoreactive inhibin levels, in prostatic cancer patients. Clinical Endocrinology $199440743-750$.

17 Christin-Maitre S \& Bouchard P. Bioassays of gonadotropins based on cloned receptors. Molecular and Cellular Endocrinology 1996 $125151-159$.

18 Christiansen C, Christiansen MS \& Transböl I. Bone mass in postmenopausal women after withdrawal of estrogen/gestagen replacement therapy. Lancet $1981 \mathbf{1} 459-461$.

19 Judd HL, Meldrum DR, Deftos LJ, Henderson BE. Hot flushes. Estrogen replacement therapy: indications and complications. Annals of Internal Medicine $1983 \mathbf{9 8} 195$.

20 Grady D, Rubin SM, Petitti DB, Fox CS, Black D, Ettinger B et al. Hormone therapy to prevent disease and prolong life in postmenopausal women. Annals of Internal Medicine 1992117 1016-1037.

21 Mijatovic V, van der Mooren MJ, Stehouwer CDA, Netelenbos JC \& Kenemans P. Postmenopausal hormone replacement, risk estimators for coronary artery disease and cardiovascular protection. Gynecological Endocrinology 199913 130-144.

22 Torgerson DJ \& Bell-Syer SE. Hormone replacement therapy and prevention of nonvertebral fracture: an analysis of randomized trials. Journal of the American Medical Association 200113 2891-2897.

23 Vihtamäki T, Savilahti R \& Tuimala R. Why do postmenopausal women discontinue hormone replacement therapy? Maturitas 199933 99-105.

24 deLignier B. Hormone replacement therapy: clinical benefits and side-effects. Maturitas 199623 S31-S36.

25 Wiklund I, Berg G, Hammar J, Karlberg J, Lindgren R, Sandin K et al. Long-term effect of transdermal hormonal therapy on aspects of quality of life in post-menopausal women. Maturitas $199214225-236$.

26 Hirvonen E, Lamberg-Allardt C, Lankinen K, Geurts P \& WilénRosenqvist G. Transdermal oestradiol gel in the treatment of the climacterium: a comparison with oral therapy. British Journal of Obstetrics and Gynaecology $1997 \mathbf{1 0 4} 19-25$.

27 Foidart J-M, Béliard A, Hedon B, Ochsenbein E, Bernard A-M, Bergeron C et al. Impact of percutaneous oestradiol gels in postmenopausal hormone replacement therapy on clinical symptoms and endometrium. British Journal of Obstetrics and Gynaecology $1997104305-310$

28 Casper RF, Yen SSC \& Wilkes MM. Menopausal flushes: a neuroendocrine link with pulsatile luteinizing hormone secretion. Science 1979205 823-825.

Received 30 August 2001

Accepted 3 December 2001 